in vivo $34: 3551-3557(2020)$

doi:10.21873/invivo.12198

\title{
Impact of Osteopenia on Oncologic Outcomes After Curative Resection for Pancreatic Cancer
}

\author{
TAKASHI MOTOMURA ${ }^{1}$, HIDEAKI UCHIYAMA ${ }^{1}$, TOMOHIRO IGUCHI ${ }^{1}$, \\ MIZUKI NINOMIYA $^{1}$, RINTARO YOSHIDA ${ }^{1}$, TAKUYA HONBOH ${ }^{1}$, \\ NORIAKI SADANAGA ${ }^{1}$, TETSURO AKASHI ${ }^{2}$ and HIROSHI MATSUURA ${ }^{1}$ \\ ${ }^{1}$ Department of Surgery, Saiseikai Fukuoka, General Hospital, Fukuoka, Japan; \\ ${ }^{2}$ Department of Internal Medicine, Saiseikai Fukuoka, General Hospital, Fukuoka, Japan
}

\begin{abstract}
Background/Aim: We evaluated the relationship between low bone mineral density (BMD), also called osteopenia, and prognosis in patients who underwent resection for pancreatic cancer $(P C)$. Patients and Methods: We enrolled 91 consecutive patients who underwent curative resections for PC between May 2009 and January 2019. Their BMDs were measured at the Th11 vertebra using computed tomography. Patients were then divided by ageadjusted standard BMD values into the osteopenia group $(n=34)$ and the non-osteopenia group $(n=57)$. Their overall survival (OS) and recurrence-free survival (RFS) were compared (log-rank test). Results: The two groups did not differ in age, BMI, tumor marker, operation time, blood loss, postoperative complications or stage. The osteopenia group had significantly worse 3-year rates for OS $(46 \%$ vs. 30\%, $p=0.04)$ and RFS (41\% vs. $26 \%, p=0.01)$. In multivariate analysis, osteopenia was an independent prognostic factor for RFS $(H R=2.16, p=0.01)$. Conclusion: Osteopenia is an adverse prognostic factor for patients with resected $P C$.
\end{abstract}

Despite improvements in surgical techniques and anti-cancer agents, the prognosis for pancreatic cancer (PC) remains dismal, with a 5-year survival rate of only $8 \%$ in the United States (1). Although resection procedures such as pancreaticoduodenectomy (PD) or distal pancreatectomy (DP) are the only curative treatments currently available, their mortality and morbidity rates are $\sim 5 \%$ and 30\%-60\%, respectively (2). Therefore, the decision to perform a

This article is freely accessible online.

Correspondence to: Takashi Motomura, MD, Ph.D., Department of Surgery, Saiseikai Fukuoka General Hospital, Fukuoka, Japan. Tel: +81 927718151, Fax: +81 927160865, e-mail: t-moto@surg2.med.kyushu-u.ac.jp

Key Words: Osteopenia, pancreatic cancer, bone marrow density. resection should be made carefully. In addition to tumor markers and staging, inflammation or immune-nutrition markers such as neutrophil-lymphocyte ratio (NLR) $(3,4)$, controlling nutritional status (CONUT) score (5), and sarcopenia $(6,7)$, have been shown to predict prognosis after PC resection. These markers and indices are now widely used for PC and other gastrointestinal and hepatobiliary malignancies (8-10).

Among these nutritional markers, osteopenia, the condition in which bone mineral density (BMD) becomes abnormally low, has recently received attention with respect to hepatobiliary cancer and PC (11-13). Although vitamin D levels are reportedly associated with prognoses of various cancers $(14,15)$. Sharma et al. have shown for the first time that osteopenia was associated with mortality after liver transplantation for hepatocellular carcinoma (HCC) (11). They measured BMD by calculating average pixel density within a circle of the eleventh thoracic vertebra (Th11), using preoperative CT images.

Using this simple method, Yao et al. have shown an inverse relationship between osteopenia and survival after resection of extrahepatic biliary malignancies (12). However, the effect of osteopenia on prognosis of patients with resected pancreatic malignancies is still unclear. This study aimed to clarify any association between osteopenia and outcomes of resections for PC.

\section{Patients and Methods}

Patients. In this study, we retrospectively enrolled 91 consecutive patients who underwent curative resections for PC at our institute between March 2009 and January 2019. The patients' demographics and clinical data were collected from electronic health records. The diagnosis of PC was confirmed by two or more pathologists. The study was approved by the ethical committee of Saiseikai Fukuoka General Hospital.

Detection of osteopenia. BMD was evaluated by preoperative CT images. We used non-contrast CT images at the Th11 level, using 
the entire vertebra body as the region of interest (ROI), to calculate BMD according to a previous report (Figure 1) (11).

We used two different BMD criteria to determine cut-off values for whether participants were osteopenic or not. The first cut-off value was the median Hounsfield unit (HU) value for the entire study cohort, which was $148 \mathrm{HU}$; patients whose BMDs were <148 $\mathrm{HU}$ or $\geq 148 \mathrm{HU}$ were considered to be osteopenic or nonosteopenic, respectively.

However, we found that using the median HU score as the cutoff value led to osteopenic and non-osteopenic groups that significantly differed by age, which we considered could confound our evaluation of patient survival and other factors. Therefore, for the second cut-off values, we calculated each patient's age-adjusted standard BMD, as described in our previous report (16), using the following formulae, which were based on data from healthy donors for living-donor liver transplantation:

BMD (HU) for men=308.82-2.49 $\times$ Age in years

BMD (HU) for women=311.84-2.41 $\times$ Age in years

Thus, we twice divided the participants into two groups-those with osteopenia, and those without osteopenia-using both sets of criteria (Tables I and II).

Measurement of skeletal muscle index. Skeletal muscle area was measured by the same CT images as described above. For the measurement, a transverse CT image at the level of third lumber vertebrae (L3) was chosen as previously described (10). All the skeletal muscle in the L3 region was quantified by manual tracing, including the psoas, the erector spinae, the quadratus lumborum, the transversus abdominis, the external and the internal oblique abdominal muscle, and the rectus abdominis muscle. Because this area is related to each patient's physical size, the measured skeletal muscle area was normalized to the patient's height (skeletal muscle index; SMI, $\mathrm{cm}^{2} / \mathrm{m}^{2}$ ).

Measurement of NLR and CONUT score. According to previous reports (3-5), NLR was calculated by dividing neutrophil counts by lymphocyte counts, using preoperative laboratory data. Similarly, CONUT scores were calculated by adding scores for albumin concentrations, lymphocyte counts and total cholesterol concentrations (albumin concentrations of $\geq 3.5,3.0-3.49,2.5-2.99$ and $<2.5 \mathrm{~g} / \mathrm{dl}$ were scored as $0,2,4$, and 6 points, respectively; total lymphocyte counts of $\geq 1600,1200-1599,800-1199$ and $<800 / \mathrm{mm}^{3}$ were scored as $0,1,2$ and 3 points, respectively; and total cholesterol concentrations $\geq 180,140-179,100-139$ and $<100 \mathrm{mg} / \mathrm{dl}$ were scored as $0,1,2,3$, respectively).

Statistical analysis. All data were analyzed using JMP ${ }^{\circledR}$ statistical software (SAS Institute, Cary, NC, USA). A $\chi^{2}$ test was performed for qualitative variables, and a Wilcoxon test was performed for quantitative variables. A log-rank test was performed for survival rates using the Kaplan-Meier method.

\section{Results}

Comparison of patients' characteristics according to median $B M D$ value. Patients were initially divided into two groups according to the median BMD value, 148 HU. Table I shows the clinicopathological factors of these two groups. The mean age of the osteopenia group $(n=45)$ was significantly

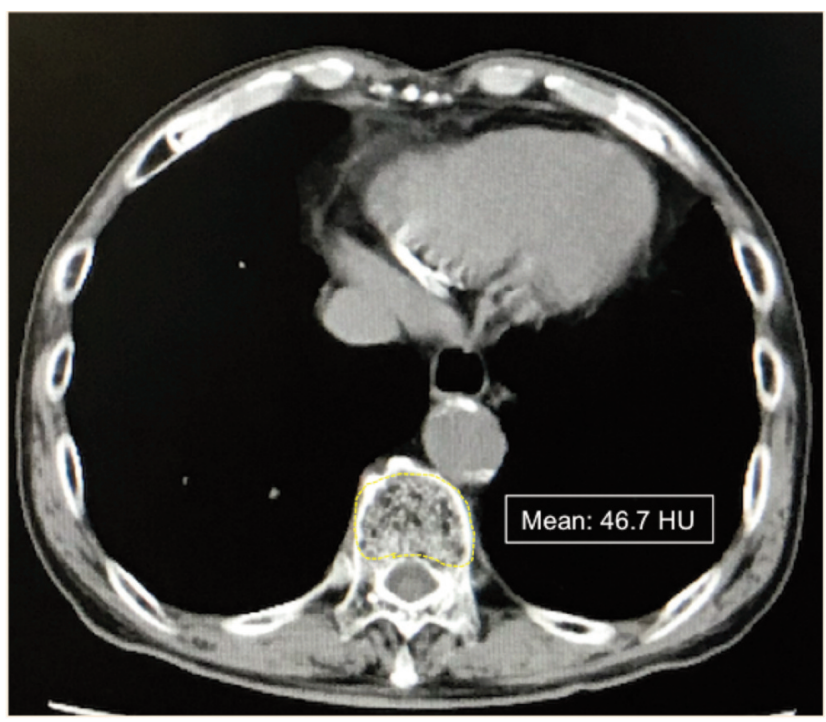

Figure 1. Non-contrast CT image at the level of Th11. A region of interest (ROI) was traced, free-hand, along the vertebra body; the mean value of density was then provided in Hounsfield units (HU).

higher than that of the non-osteopenia group $(n=46)(75 \mathrm{vs}$. $68, p=0.001)$. The osteopenia group also had a lower mean hemoglobin level (12.2 vs. 13.0, $p=0.01)$. Thirty osteopenia patients and 31 non-osteopenia patients had tubular adenocarcinoma; other patients had adenosquamous carcinoma, acinar cell carcinoma, malignant mucinous cystic neoplasm, or neuroendocrine carcinoma. The two groups did not significantly differ in tumor pathology or staging. However, a significantly lower percentage of the osteopenia group underwent post-operative adjuvant chemotherapy.

Three-years OS and RFS were both significantly worse in the osteopenia group (OS rate: $47.6 \%$ vs. $26.6 \%, p=0.006$; RFS rate: $45.4 \%$ vs. $25.8 \%, p=0.008)$.

However, as differences in age could influence these results, we evaluated the participants again, following categorization according to their age-adjusted standard BMD.

Comparison of patients' characteristics by their age-adjusted standard BMD. To decrease the influence of age on our findings, we calculated the standard age-adjusted BMD for each patient as previously described (16). Patients whose BMDs were less than their age-adjusted standard values were considered to have osteopenia. Table II shows the clinicopathological factors of the age-adjusted osteopenia group $(n=34)$ and non-osteopenia group $(n=57)$. The two groups did not significantly differ in age, tumor pathology or staging, or other clinical factors. However, mean hemoglobin levels were again lower in the osteopenia group (12.1 vs. 13.0, $p=0.006$ ).

Among immune and inflammatory-nutritional markers, SMI tended to be lower in the age-adjusted osteopenia 
Table I. Clinicopathological factors of patients with and without osteopenia, using median BMD (148 HU) as the cut-off.

\begin{tabular}{|c|c|c|c|}
\hline & $\begin{array}{c}\text { Osteopenia }(\mathrm{BMD}<148 \mathrm{HU}) \\
\qquad(\mathrm{n}=45)\end{array}$ & $\begin{array}{l}\text { Non-osteopenia }(\mathrm{BMD} \geq 148 \mathrm{HU}) \\
(\mathrm{n}=46)\end{array}$ & $p$-Value \\
\hline \multicolumn{4}{|l|}{ Patient clinical background } \\
\hline Age (y), mean (min.-max.) & $75(49-90)$ & $68(41-85)$ & 0.001 \\
\hline Sex (male/female), $\mathrm{n}$ & $21 / 24$ & $27 / 19$ & 0.31 \\
\hline BMI $\left(\mathrm{kg} \times \mathrm{m}^{-2}\right)$, mean $\pm \mathrm{SD}$ & $22.0 \pm 0.5$ & $22.3 \pm 0.5$ & 0.69 \\
\hline White blood cell $(/ \mu \mathrm{l})$, mean $\pm \mathrm{SD}$ & $6297 \pm 289$ & $5879 \pm 281$ & 0.30 \\
\hline Hemoglobin $(\mathrm{g} / \mathrm{dl})$, mean \pm SD & $12.2 \pm 0.2$ & $13.0 \pm 0.2$ & 0.01 \\
\hline Albumin $(\mathrm{g} / \mathrm{dl})$, mean $\pm \mathrm{SD}$ & $3.8 \pm 0.08$ & $3.9 \pm 0.08$ & 0.32 \\
\hline Total cholesterol $(\mathrm{mg} / \mathrm{dl})$, mean $\pm \mathrm{SD}$ & $191 \pm 14$ & $201 \pm 13$ & 0.62 \\
\hline $\mathrm{CRP}(\mathrm{mg} / \mathrm{dl})$, mean $\pm \mathrm{SD}$ & $0.40 \pm 0.2$ & $1.1 \pm 0.2$ & 0.06 \\
\hline CEA $(\mathrm{mg} / \mathrm{dl})$, mean $\pm \mathrm{SD}$ & $4.1 \pm 0.5$ & $3.6 \pm 0.5$ & 0.30 \\
\hline CA19-9 (IU/ml), mean \pm SD & $428 \pm 124$ & $167 \pm 121$ & 0.13 \\
\hline $\operatorname{SMI}\left(\mathrm{m}^{2} \times \mathrm{cm}^{-2}\right)$ & $20.7 \pm 1.0$ & $22.8 \pm 1.0$ & 0.13 \\
\hline Neoadjuvant chemotherapy (yes/no), n & $1 / 44$ & $3 / 43$ & 0.29 \\
\hline Adjuvant chemotherapy (yes/no), n & $13 / 32$ & $26 / 10$ & 0.006 \\
\hline Clavien-Dindo $\geq 3, \mathrm{n}(\%)$ & $6(13.2)$ & $3(6.0)$ & 0.21 \\
\hline \multicolumn{4}{|l|}{ Operative factor } \\
\hline Procedure (PD/DP/others), $\mathrm{n}$ & $32 / 9 / 4$ & $34 / 9 / 3$ & 0.99 \\
\hline Operative time (min), mean \pm SD & $522 \pm 27$ & $546 \pm 26$ & 0.52 \\
\hline Intraoperative bleeding $(\mathrm{ml})$, mean $\pm \mathrm{SD}$ & $946 \pm 150$ & $984 \pm 146$ & 0.86 \\
\hline Intraoperative transfusion (yes, no), $\mathrm{n}$ & $15 / 30$ & $9 / 37$ & 0.16 \\
\hline \multicolumn{4}{|l|}{ Pathological factor } \\
\hline Adenocarcinoma/IPMC/others, $\mathrm{n}$ & $30 / 10 / 5$ & $31 / 12 / 3$ & 0.21 \\
\hline Maximum tumor size $(\mathrm{cm})$, mean \pm SD & $3.1 \pm 0.2$ & $3.3 \pm 0.2$ & 0.50 \\
\hline Lymph node metastasis (yes/no), n & $20 / 25$ & $23 / 23$ & 0.44 \\
\hline Anterior peritoneum invasion (yes/no), $\mathrm{n}$ & $17 / 28$ & $15 / 31$ & 0.53 \\
\hline Retroperitoneal invasion (yes/no), $\mathrm{n}$ & $33 / 12$ & $31 / 15$ & 0.29 \\
\hline Nerve plexus invasion (yes/no), $\mathrm{n}$ & $7 / 38$ & $7 / 39$ & 0.53 \\
\hline Arterial invasion (yes/no), & $1 / 44$ & $2 / 44$ & 0.55 \\
\hline Portal vein invasion (yes/no), $\mathrm{n}$ & $8 / 37$ & $12 / 34$ & 0.74 \\
\hline
\end{tabular}

BMI: Body mass index; CRP: C-reactive protein; CEA: carcinoembryonic antigen; CA19-9: carbohydrate antigen 19-9; SMI: skeletal muscle index; PD: pancreaticoduodenectomy; DP: distal pancreatectomy; IPMC: intraductal papillary mucinous carcinoma.

group, but not significantly so. Mean NLR, CRP and CONUT scores did not significantly differ between the two age-adjusted groups.

Survival rate with or without age-adjusted osteopenia. Three-year OS was $46 \%$ in the non-age-adjusted osteopenia group and $30 \%$ in the age-adjusted osteopenia group $(p=0.04 ;$ Figure 2A). This difference was even more pronounced for the 3-year RFS in the non-age-adjusted osteopenia group $(41 \%)$ than in the age-adjusted osteopenia group $(26 \%, p=0.01$; Figure $2 \mathrm{~B})$. These findings suggest that, rather than an unrelated comorbidity, or nonspecific indicator of impaired general condition, osteopenia is significantly associated with cancer recurrence

In univariate analysis, age-adjusted osteopenia, tumor differentiation, anterior surface invasion, retroperitoneum invasion, portal vein invasion, nerve plexus invasion and lymph node metastasis were associated with shorter RFS after resection for PC (Table III). Multivariate analysis found age-adjusted osteopenia to be independently associated with worse RFS after resection for PC.

\section{Discussion}

This study shows, for the first time, that osteopenia has a negative impact on long-term outcomes after curative resection for malignant pancreatic tumors.

At first, we set the cut-off value for BMD at 148 HU-the median value for our study cohort. Although the osteopenia group exhibited worse outcomes, we could not deny the possibility of confounding bias due to the significant difference in age between the two groups. We, therefore, calculated ageadjusted standard BMD values for each patient, according to a formula that was established using data from healthy living organ donors (16). The age-adjusted osteopenia group still showed worse OS and RFS. Our findings imply that osteopenia is not merely a comorbidity but is associated with cancer recurrence among patients with pancreatic malignancies. 
Table II. Clinicopathological factors of patients with and without osteopenia, using age-adjusted standard BMD values as the cut-off.

\begin{tabular}{|c|c|c|c|}
\hline & $\begin{array}{l}\text { Age adjusted-Osteopenia } \\
\qquad(\mathrm{n}=34)\end{array}$ & $\begin{array}{l}\text { Non-osteopenia } \\
\quad(\mathrm{n}=57)\end{array}$ & $p$-Value \\
\hline \multicolumn{4}{|l|}{ Patient clinical background } \\
\hline Age (y), mean (min.-max.) & $72(41-90)$ & $71(51-89)$ & 0.60 \\
\hline Gender (male/female), $\mathrm{n}$ & $13 / 21$ & $35 / 22$ & 0.03 \\
\hline 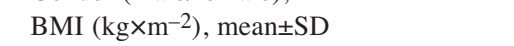 & $22.1 \pm 0.5$ & $21.5 \pm 0.5$ & 0.31 \\
\hline White blood cell $(/ \mu \mathrm{l})$, mean $\pm \mathrm{SD}$ & $6085 \pm 305$ & $6180 \pm 236$ & 0.85 \\
\hline Hemoglobin $(\mathrm{g} / \mathrm{dl})$, mean \pm SD & $12.1 \pm 0.2$ & $13.0 \pm 0.2$ & 0.006 \\
\hline $\mathrm{NLR}$, mean $\pm \mathrm{SD}$ & $2.79 \pm 0.25$ & $2.67 \pm 0.19$ & 0.71 \\
\hline CONUT score, mean \pm SD & $2.1 \pm 0.3$ & $1.7 \pm 0.2$ & 0.20 \\
\hline $\mathrm{CRP}(\mathrm{mg} / \mathrm{dl})$, mean $\pm \mathrm{SD}$ & $0.47 \pm 0.3$ & $0.94 \pm 0.2$ & 0.22 \\
\hline $\mathrm{CEA}(\mathrm{mg} / \mathrm{dl})$, mean $\pm \mathrm{SD}$ & $3.6 \pm 0.6$ & $4.1 \pm 0.4$ & 0.53 \\
\hline CA19-9 (IU/ml), mean \pm SD & $500 \pm 126$ & $187 \pm 110$ & 0.44 \\
\hline SMI $\left(\mathrm{m}^{2} \times \mathrm{cm}^{-2}\right)$ & $20.1 \pm 1.0$ & $22.8 \pm 0.9$ & 0.06 \\
\hline Neoadjuvant chemotherapy (yes/no), n & $2 / 32$ & $2 / 45$ & 0.74 \\
\hline Adjuvant chemotherapy (yes/no), n & $10 / 24$ & $24 / 23$ & 0.05 \\
\hline Clavien-Dindo $\geq 3, \mathrm{n}(\%)$ & $3(8.8)$ & $6(10.5)$ & 0.79 \\
\hline \multicolumn{4}{|l|}{ Operative factor } \\
\hline Procedure (PD/DP/others), $\mathrm{n}$ & $24 / 9 / 1$ & $41 / 10 / 6$ & 0.26 \\
\hline Operative time $(\mathrm{min}), \operatorname{mean} \pm \mathrm{SD}$ & $499 \pm 30$ & $504 \pm 23$ & 0.88 \\
\hline Intraoperative bleeding $(\mathrm{ml})$, mean $\pm \mathrm{SD}$ & $899 \pm 157$ & $980 \pm 157$ & 0.68 \\
\hline Intraoperative transfusion (yes, no), $\mathrm{n}$ & $10 / 24$ & $14 / 43$ & 0.61 \\
\hline \multicolumn{4}{|l|}{ Pathological factor } \\
\hline Adenocarcinoma/IPMC/others, $\mathrm{n}$ & $24 / 5 / 5$ & $37 / 17 / 3$ & 0.10 \\
\hline Maximum tumor size $(\mathrm{cm})$, mean \pm SD & $3.2 \pm 0.2$ & $3.2 \pm 0.2$ & 0.94 \\
\hline Lymph node metastasis (yes/no), $n$ & $20 / 14$ & $27 / 30$ & 0.38 \\
\hline Anterior peritoneum invasion (yes/no), $\mathrm{n}$ & $12 / 22$ & $18 / 39$ & 0.75 \\
\hline Retroperitoneal invasion (yes/no), $\mathrm{n}$ & $27 / 7$ & $36 / 21$ & 0.12 \\
\hline Nerve plexus invasion (yes/no), $\mathrm{n}$ & $7 / 27$ & $7 / 50$ & 0.43 \\
\hline Arterial invasion (yes/no), & $1 / 33$ & $2 / 55$ & 0.91 \\
\hline Portal vein invasion (yes/no), $\mathrm{n}$ & $6 / 28$ & $14 / 43$ & 0.45 \\
\hline
\end{tabular}

BMI: Body mass index; CRP: C-reactive protein; CEA: carcinoembryonic antigen; CA19-9: carbohydrate antigen 19-9; SMI: skeletal muscle index; PD: pancreaticoduodenectomy; DP: distal pancreatectomy; IPMC: intraductal papillary mucinous carcinoma.

Sarcopenia and frailty have recently received much attention among clinical oncologists, but the role of osteopenia in oncologic outcomes is less widely studied. As decreased BMD is associated with menopause and antiestrogen treatments, breast oncologists may pay more attention to osteopenia; several reports have shown a correlation between osteopenia and breast cancer prognosis $(17,18)$. Similarly, osteopenia has also been reported during anti-androgen therapy for prostate cancer patients (19).

The European Society of Medical Oncology has published a guideline for managing bone health in cancer patients (20). This guideline, however, first addresses the management of patients with bone metastasis arising from various solid tumors. Secondly, the guideline addresses the negative effects of anti-cancer therapies (such as chemotherapy and radiation) on reproductive hormones that are crucial for the maintenance of bone remodeling. The study of Dumanskiy et al. on bone metabolism in lung cancer patients has shown that they had significantly higher serum levels of some macro- and microelements (such as cobalt, lithium, and phosphorus) compared with healthy controls (21). Conversely, calcium and magnesium were significantly lower. These findings may reflect abnormal bone metabolism associated with osteopenia and osteoporosis in various cancers, which often result in bone fractures, and negatively impact patients' quality of life. However, this report did not show correlations with longterm survival, or with cancer recurrence.

Interestingly, the correlation of osteopenia with poor cancer prognosis after resection has been reported for HCC (11), and biliary cancer (12), in addition to breast cancer. To our knowledge, the current study is the first to show an association of osteopenia with worse survival after PC resection Although the mechanism of this relationship is unclear, osteopenia might be associated with some inflammatory cytokines, as with sarcopenia (22). However, whether osteopenia is the result of advanced malignancy or the cause of worse prognosis is unclear. In the current study, 
A

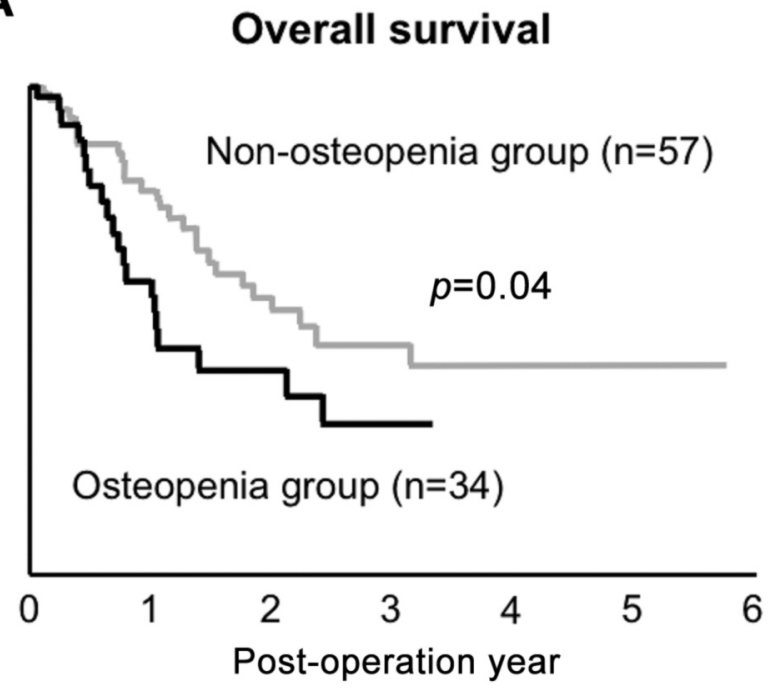

B

Recurrence free survival

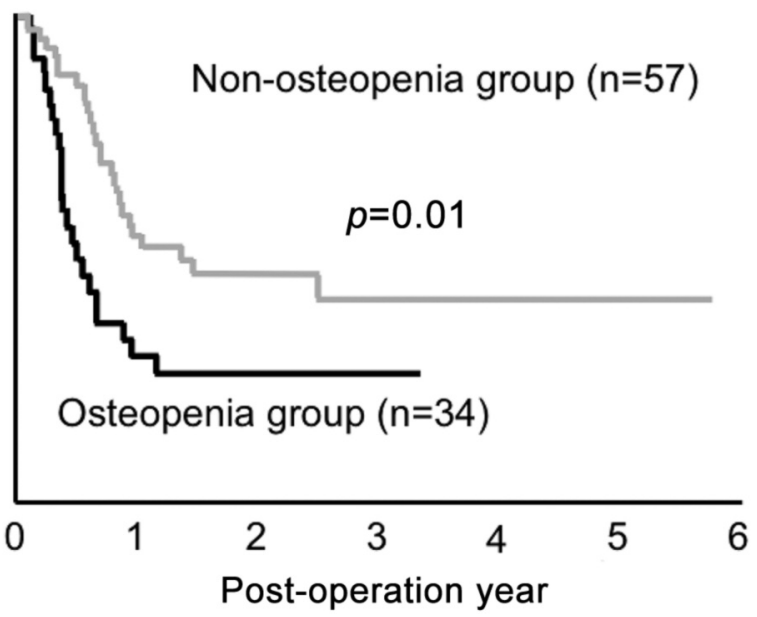

Figure 2. Comparison of overall survival (OS) and recurrence-free survival (RFS) rates between patients with osteopenia and those without osteopenia (age-adjusted). (A) OS was significantly worse in osteopenia group; and (B) age-adjusted osteopenia was a significant risk factor for pancreatic cancer recurrence.

Table III. Univariate and multivariate analyses of factors that affect pancreatic cancer recurrence after curative resection.

\begin{tabular}{|c|c|c|c|c|}
\hline \multirow[t]{2}{*}{ Variables } & \multicolumn{2}{|c|}{ Univariate analysis } & \multicolumn{2}{|c|}{ Multivariate analysis } \\
\hline & HR $(95 \% \mathrm{CI})$ & $p$-Value & HR $(95 \% \mathrm{CI})$ & $p$-Value \\
\hline Age $\geq 70$ & $1.06(0.61-1.91)$ & 0.82 & & \\
\hline Gender (male) & $0.94(0.54-1.66)$ & 0.85 & & \\
\hline $\mathrm{BMI} \geq 24 \mathrm{~kg} / \mathrm{m}^{2}$ & $1.61(0.83-2.91)$ & 0.14 & & \\
\hline Preoperative diabetes (yes) & $0.99(0.55-1.74)$ & 0.97 & & \\
\hline CA19-9 $\geq 50 \mathrm{U} / \mathrm{ml}$ & $1.32(0.76-2.33)$ & 0.32 & & \\
\hline NLR $\geq 3$ & $1.19(0.64-2.11)$ & 0.55 & & \\
\hline CONUT score $\geq 3$ & $1.35(0.58-2.74)$ & 0.45 & & \\
\hline Sarcopenia (yes) & $2.03(1.15-3.54)$ & 0.16 & & \\
\hline Age-adjusted osteopenia (yes) & $1.37(0.71-2.39)$ & 0.01 & $2.16(1.14-4.08)$ & 0.01 \\
\hline Intraoperative transfusion (yes) & $1.37(0.71-2.39)$ & 0.31 & & \\
\hline POPF (yes) & $0.96(0.49-1.76)$ & 0.91 & & \\
\hline Clavien-Dindo $\geq 3$ & $2.11(0.80-4.60)$ & 0.11 & & \\
\hline Adjuvant chemotherapy (yes) & $1.61(0.92-2.85)$ & 0.09 & & \\
\hline Tumor differentiation (poorly) & $3.24(1.51-6.32)$ & 0.0003 & $3.13(1.38-6.63)$ & 0.007 \\
\hline Anterior surface invasion (yes) & $2.07(1.16-3.63)$ & 0.01 & $1.23(0.65-2.27)$ & 0.51 \\
\hline Retroperitoneum invasion (yes) & $4.86(2.31-11.9)$ & $<0.0001$ & $3.36(1.29-10.1)$ & 0.01 \\
\hline Portal vein invasion (yes) & $2.21(1.15-4.02)$ & 0.02 & $2.29(1.10-4.63)$ & 0.02 \\
\hline Arterial invasion (yes) & $1.86(0.45-5.14)$ & 0.34 & & \\
\hline Nerve plexus invasion (yes) & $2.39(1.16-4.58)$ & 0.02 & $1.44(0.64-3.05)$ & 0.35 \\
\hline Lymph node metastasis (yes) & $2.70(1.53-4.92)$ & 0.0006 & $1.09(0.56-2.21)$ & 0.79 \\
\hline
\end{tabular}

BMI: Body mass index; CA19-9: carbohydrate antigen 19-9; CI: confidence interval; CONUT: controlling nutritional status; HR: hazard ratio; NLR: neutrophil-lymphocyte ratio; POPF: post-operative pancreatic fistula.

age-adjusted osteopenia was inversely associated with both OS and RFS, which strongly suggests that osteopenia is not simply the result of a systemic impairment (such as cachexia) but is associated with some tumor factors.
Qiu et al. have shown the NF-kB is possibly the cause of sarcopenia (23). Interestingly, high expression of receptor activator of NF-kB ligand (RANKL) has recently been reported to increase the risk of bone metastasis in breast 
cancer patients (24). NF-kB is reportedly a key molecule in the progression of both biliary cancer and PC (25-27). Together, these findings suggest that NF-KB could affect the relationships between sarcopenia and osteopenia and poor prognosis of biliary cancer and PC.

Therapeutic management of osteopenia warrants wider attention. A bisphosphonate, zoledronate, has shown to prevent fractures in women with osteopenia (28). Surprisingly, this bisphosphonate also improved survival in breast cancer patients when used as an adjuvant therapy (29). Although bisphosphonates could not be concluded to lengthen OS or RFS in patients with PC, their involvement should be studied further.

This study is limited by its retrospective, single-center design and its small cohort. Age-adjustment for BMD decreased the age-related bias for osteopenia outcomes, but sex and hemoglobin levels may still be confounding factors. The percentage of patients who underwent adjuvant chemotherapy tended to be smaller in the osteopenia group, but not significantly so. However, multivariate analysis still demonstrated the significance of age-adjusted osteopenia for cancer recurrence.

In conclusion, this is the first report to show that ageadjusted osteopenia is associated with worse prognosis after resection for $\mathrm{PC}$, which suggests that monitoring bone density might be a useful tool in managing this most challenging disease.

\section{Conflicts of Interest}

The Authors of this manuscript declare that they have no competing interests regarding this work.

\section{Authors' Contributions}

Takashi Motomura performed the operations, collected and analyzed the data, wrote and edited the manuscript. Hideaki Uchiyama performed the operations, checked and revised the manuscript. Tomohiro Iguchi checked and revised the manuscript. Mizuki Ninomiya performed the operations and collected the data. Rintaro Yoshida performed the operations. Takuya Honboh performed the operations. Noriaki Sadanaga performed the operations and checked the manuscript. Tetsuro Akashi tested and diagnosed the patients. Hiroshi Matsuura supervised the entire work.

\section{Acknowledgements}

The Authors thank Marla Brunker, from Edanz Group (www.edanzediting.com/ac), for editing a draft of this manuscript.

\section{References}

1 Siegel RL, Miller KD and Jemal A: Cancer statistics 2018. CA Cancer J Clin 68(1): 7-30, 2018. PMID: 29313949. DOI: $10.3322 /$ caac. 21442
2 Khalili M, Morano WF, Marconcini L, Shaikh MF, Gleeson EM, Styler M, Zebrower M and Bowne WB: Multidisciplinary strategies in bloodless medicine and surgery for patients undergoing pancreatectomy. J Surg Res 229: 208e215, 2018. PMID: 29936992. DOI: 10.1016/j.jss.2018.04.009

3 Tsujita E, Ikeda Y, Kinjo N, Yamashita YI, Hisano T, Furukawa M, Taguchi KI, Morita M, Toh Y and Okamura T: Postoperative neutrophil-to-lymphocyte ratio as a predictor of long-term prognosis after pancreatectomy for pancreatic carcinoma: a retrospective analysis. Am Surg 83(6): 610-616, 2017. PMID: 28637563.

4 Abe T, Nakata K, Kibe S, Mori Y, Miyasaka Y, Ohuchida K, Ohtsuka T, Oda Y and Nakamura M: Prognostic value of preoperative nutritional and immunological factors in patients with pancreatic ductal adenocarcinoma. Ann Surg Oncol 25(13): 3996-4003, 2018. PMID: 30225838. DOI: 10.1245/s10434-0186761-6

5 Kato Y, Yamada S, Suenaga M, Takami H, Niwa Y, Hayashi M, Iwata N, Kanda M, Tanaka C, Nakayama G, Koike M, Fujiwara $\mathrm{M}$ and Kodera Y: Impact of the controlling nutritional status score on the prognosis after curative resection of pancreatic ductal adenocarcinoma. Pancreas 47(7): 823-829, 2018. PMID: 29975352. DOI: 10.1097/MPA.0000000000001105

6 Peng P, Hyder O, Firoozmand A, Kneuertz P, Schulick RD, Huang D, Makary M, Hirose K, Edil B, Choti MA, Herman J, Cameron JL, Wolfgang CL and Pawlik TM: Impact of sarcopenia on outcomes following resection of pancreatic adenocarcinoma J Gastrointest Surg 16(8): 1478-1486, 2012. PMID: 22692586. DOI: 10.1007/s11605-012-1923-5

7 Mintziras I, Miligkos M, Wächter S, Manoharan J, Maurer E and Bartsch DK: Sarcopenia and sarcopenic obesity are significantly associated with poorer overall survival in patients with pancreatic cancer: Systematic review and meta-analysis. Int J Surg 59: 19-26, 2018. PMID: 30266663. DOI: 10.1016/j.ijsu. 2018.09.014

8 Motomura T, Shirabe K, Mano Y, Muto J, Toshima T, Umemoto Y, Fukuhara T, Uchiyama H, Ikegami T, Yoshizumi T, Soejima Y and Maehara Y: Neutrophil-lymphocyte ratio reflects hepatocellular carcinoma recurrence after liver transplantation via inflammatory microenvironment. J Hepatol 58(1): 58-64, 2013. PMID: 22925812. DOI: 10.1016/j.jhep.2012.08.017

9 Harimoto N, Yoshizumi T, Inokuchi S, Itoh S, Adachi E, Ikeda Y, Uchiyama H, Utsunomiya T, Kajiyama K, Kimura K, Kishihara F, Sugimachi K, Tsujita E, Ninomiya M, Fukuzawa K, Maeda T, Shirabe K and Maehara Y: Prognostic significance of preoperative controlling nutritional status (conut) score in patients undergoing hepatic resection for hepatocellular carcinoma: a multi-institutional study. Ann Surg Oncol 25(11): 3316-3323, 2018. PMID: 30051372. DOI: 10.1245/s 10434-0186672-6

10 Harimoto N, Shirabe K, Yamashita YI, Ikegami T, Yoshizumi T, Soejima Y, Ikeda T, Maehara Y, Nishie A and Yamanaka T: Sarcopenia as a predictor of prognosis in patients following hepatectomy for hepatocellular carcinoma. Br J Surg 100(11): 1523-1530, 2013. PMID: 24037576. DOI: 10.1002/bjs.9258

11 Sharma P, Parikh ND, Yu J, Barman P, Derstine BA, Sonnenday CJ, Wang SC and Su GL: Bone mineral density predicts posttransplant survival among hepatocellular carcinoma liver transplant recipients. Liver Transpl 22(8): 1092-1098, 2016. PMID: 27064263. DOI: 10.1002/lt.24458 
12 Yao S, Kaido T, Okumura S, Iwamura S, Miyachi Y, Shirai H, Kobayashi A, Hamaguchi Y, Kamo N, Uozumi R, Yagi S and Uemoto S: Bone mineral density correlates with survival after resection of extrahepatic biliary malignancies. Clin Nutr 38(6): 27702777, 2019. PMID: 30595376. DOI: 10.1016/j.clnu.2018.12.004

13 Yamada D, Eguchi H, Iwagami Y, Mukai Y, Hashimoto Y, Asaoka T, Noda T, Kawamoto K, Gotoh K, Kobayashi S, Takeda Y, Tanemura M, Mori M and Doki Y: Patients treated with preoperative chemoradiation for pancreatic ductal adenocarcinoma have impaired bone density, a predictor of distant metastasis. Ann Surg Oncol 24(12): 3715-3724, 2017. PMID: 28849575. DOI: 10.1245/s10434-017-6040-y

14 Ma Y, Zhang P, Wang F, Yang J, Liu Z and Qin H: Association between vitamin $\mathrm{D}$ and risk of colorectal cancer: a systematic review of prospective studies. J Clin Oncol 29(28): 3775-3782, 2011. PMID: 21876081. DOI: 10.1200/JCO.2011.35.7566

15 Fedirko V, Duarte-Salles T, Bamia C, Trichopoulou A, Aleksandrova K, Trichopoulos D, Trepo E, Tjønneland A, Olsen A, Overvad K, Boutron-Ruault MC, Clavel-Chapelon F, Kvaskoff M, Kühn T, Lukanova A, Boeing H, Buijsse B, Klinaki E, Tsimakidi C, Naccarati A, Tagliabue G, Panico S, Tumino R, Palli D, Bueno-de-Mesquita HB, Siersema PD, Peters PH, Lund E, Brustad M, Olsen KS, Weiderpass E, Zamora-Ros R, Sánchez MJ, Ardanaz E, Amiano P, Navarro C, Quirós JR, Werner M, Sund M, Lindkvist B, Malm J, Travis RC, Khaw KT, Stepien M, Scalbert A, Romieu I, Lagiou P, Riboli E and Jenab M: Prediagnostic circulating vitamin D levels and risk of hepatocellular carcinoma in European populations: a nested case-control study. Hepatology 60(4): 1222-1230, 2014. PMID: 24644045. DOI: 10.1002/hep.27079

16 Toshima T, Yoshizumi T, Ikegami T, Harada N, Itoh S, Mano Y, Motomura T, Soejima Y and Maehara Y: Impact of osteopenia in liver cirrhosis: special reference to standard bone mineral density with age. Anticancer Res 38(11): 6465-6471, 2018. PMID: 30396973. DOI: 10.21873/anticanres.13009

17 Ramin C, May BJ, Roden RBS, Orellana MM, Hogan BC, McCullough MS, Petry D, Armstrong DK and Visvanathan K: Evaluation of osteopenia and osteoporosis in younger breast cancer survivors compared with cancer-free women: a prospective cohort study. Breast Cancer Res 20(1): 134, 2018. PMID: 30424783. DOI: 10.1186/s13058-018-1061-4

18 Lumachi F, Basso SMM, Camozzi V, Spaziante R, Ubiali P and Ermani M: Bone mineral density as a potential predictive factor for luminal-type breast cancer in postmenopausal women. Anticancer Res 38(5): 3049-3054, 2018. PMID: 29715139. DOI: 10.21873 /anticanres.12561

19 Poulsen MH, Frost M, Abrahamsen B, Gerke O, Walter S and Lund L: Osteoporosis and prostate cancer; a 24-month prospective observational study during androgen deprivation therapy. Scand J Urol 53(1): 34-39, 2019. PMID: 30777478. DOI: $10.1080 / 21681805.2019 .1570328$

20 Coleman R, Body JJ, Aapro M, Hadji P, Herrstedt J and ESMO Guidelines Working Group: Bone health in cancer patients: ESMO Clinical Practice Guidelines. Ann Oncol 25: iii124-37, 2014. PMID: 24782453. DOI: 10.1093/annonc/mdu 103

21 Dumanskiy YV, Syniachenko OV, Stepko PA, Taktashov GS, Chernyshova OY and Stoliarova OY: The state of bone metabolism in lung cancer patients. Exp Oncol 40(2): 136-139, 2018. PMID: 29949526.
22 Li CW, Yu K, Shyh-Chang N, Li GX, Jiang LJ, Yu SL, Xu LY, Liu RJ, Guo ZJ, Xie HY, Li RR, Ying J, Li K and Li DJ: Circulating factors associated with sarcopenia during ageing and after intensive lifestyle intervention. J Cachexia Sarcopenia Muscle 10(3): 586-600, 2019. PMID: 30969486. DOI: 10.1002/ jcsm. 12417

23 Qiu J, Thapaliya S, Runkana A, Yang Y, Tsien C, Mohan ML, Narayanan A, Eghtesad B, Mozdziak PE, McDonald C, Stark GR, Welle S, Naga Prasad SV and Dasarathy S: Hyperammonemia in cirrhosis induces transcriptional regulation of myostatin by an NF-kB-mediated mechanism. Proc Natl Acad Sci USA 110(45): 18162-18167, 2013. PMID: 24145431. DOI: $10.1073 /$ pnas. 1317049110

24 Rachner TD, Kasimir-Bauer S, Göbel A, Erdmann K, Hoffmann O, Browne A, Wimberger P, Rauner M, Hofbauer LC, Kimmig $\mathrm{R}$ and Bittner AK: Prognostic value of RANKL/OPG serum levels and disseminated tumor cells in nonmetastatic breast cancer. Clin Cancer Res 25(4): 1369-1378, 2019. PMID: 30425091. DOI: 10.1158/1078-0432.CCR-18-2482

25 Sclabas GM, Fujioka S, Schmidt C, Evans DB and Chiao PJ: NF-kB in pancreatic cancer. Int J Gastrointest Cancer 33(1): 1526, 2003. PMID: 12909735. DOI: 10.1385/IJGC:33:1:15

26 Srikoon P, Kariya R, Kudo E, Goto H, Vaeteewoottacharn K, Taura M, Wongkham S and Okada S: Diethyldithiocarbamate suppresses an NF-kB dependent metastatic pathway in cholangiocarcinoma cells. Asian Pac J Cancer Prev 14(7): 44414446, 2013. PMID: 23992017. DOI: 10.7314/apjcp.2013. 14.7.4441

27 Furukawa K, Uwagawa T, Haruki K, Fujiwara Y, Iida T, Shiba $\mathrm{H}$, Misawa $\mathrm{T}$, Ohashi $\mathrm{T}$ and Yanaga $\mathrm{K}$ : Nuclear factor $\mathrm{kB}$ activity correlates with the progression and prognosis of pancreatic cancer in a mouse model. Surg Today 43(2): 171-177, 2013. PMID: 22892758. DOI: 10.1007/s00595-012-0279-5

28 Reid IR, Horne AM, Mihov B, Stewart A, Garratt E, Wong S, Wiessing KR, Bolland MJ, Bastin S and Gamble GD: Fracture prevention with zoledronate in older women with osteopenia. N Engl J Med 379(25): 2407-2416, 2018. PMID: 22892758. DOI: 10.1007/s00595-012-0279-5

29 Gnant M, Mlineritsch B, Stoeger H, Luschin-Ebengreuth G, Heck D, Menzel C, Jakesz R, Seifert M, Hubalek M, Pristauz G, Bauernhofer T, Eidtmann H, Eiermann W, Steger G, Kwasny W, Dubsky P, Hochreiner G, Forsthuber EP, Fesl C and Greil R: Adjuvant endocrine therapy plus zoledronic acid in premenopausal women with early-stage breast cancer: 62-month follow-up from the ABCSG-12 randomised trial. Lancet Oncol 12(7): 631-641, 2011. PMID: 21641868. DOI: 10.1016/S14702045(11)70122-X
Received August 25, 2020

Revised September 28, 2020 Accepted September 29, 2020 